\title{
Effect of Cyclooxygenase and Lipoxygenase Products on Pulmonary Function in Group B Streptococcal Sepsis ${ }^{1}$
}

\author{
CLEIDE SUGUIHARA, RONALD N. GOLDBERG, DOROTHY HEHRE, ALDO BANCALARI, AND \\ EDUARDO BANCALARI \\ Department of Pediatrics, Division of Neonatology, University of Miami School of Medicine, Miami, \\ Florida 33101
}

\begin{abstract}
The effects of the cyclooxygenase inhibitor, indomethacin, and the leukotriene receptor antagonist, FPL 57231, on changes in dynamic lung compliance and pulmonary resistance associated with a 1-h infusion of live group B streptococci were evaluated in mechanically ventilated piglets. To define mediators of early changes in lung function, animals were given an infusion of either FPL 57231 or indomethacin beginning $15 \mathrm{~min}$ after the infusion of group B streptococci was begun. These groups were compared to an untreated group who received only group B streptococci. Within $15 \mathrm{~min}$ of starting the bacterial infusion, all groups showed significant increases in pulmonary artery pressure, pulmonary artery wedge pressure, total pulmonary resistance, transpulmonary pressure, and thromboxane $B_{2}$, and decreases in tidal volume, dynamic lung compliance, and $\mathrm{PaO}_{2}$. After treatment with indomethacin there were significant decreases in pulmonary artery pressure (mean $\pm S E M ; 48 \pm 1$ to $22 \pm 3 \mathrm{~mm} \mathrm{Hg}$, $p<0.001)$, pulmonary artery wedge pressure $(7.5 \pm 1.3$ to $2.2 \pm 0.4 \mathrm{~mm} \mathrm{Hg}, p<0.001)$ and thromboxane $B_{2}(6.51$ \pm 1.56 to $1.01 \pm 0.27 \mathrm{ng} / \mathrm{ml}, p<0.01)$ and an increase in dynamic lung compliance $(1.10 \pm 0.10$ to $1.28 \pm 0.14 \mathrm{ml} /$ $\mathrm{cm} \mathrm{H}_{2} \mathrm{O} / \mathrm{kg}, p<0.01$ ) over the study period. Total pulmonary resistance decreased significantly $(18.7 \pm 1.8$ to $15.7 \pm 1.5 \mathrm{~cm} \mathrm{H}_{2} \mathrm{O} /$ liter $/ \mathrm{s}, p<0.02$ ) only at $60 \mathrm{~min}$. In animals treated with FPL 57231 only pulmonary artery pressure ( $46 \pm 3$ to $30 \pm 2 \mathrm{~mm} \mathrm{Hg}, p<0.05$ ) and pulmonary artery wedge pressure $(7.5 \pm 0.8$ to $4.0 \pm 0.9$ $\mathrm{mm} \mathrm{Hg}, p<0.01$ ) decreased. These data suggest that cyclooxygenase products of arachidonic acid metabolism play a role in the early changes in pulmonary mechanics in group B streptococci sepsis. (Pediatr Res 22: 478-482, 1987)
\end{abstract}

\section{Abbreviations}

Cdyn, dynamic lung compliance

GBS, group B streptococci

Ppa, pulmonary artery pressure

Ppaw, pulmonary artery wedge pressure

Psa, systemic arterial pressure

$\mathbf{R}_{\mathrm{L}}$, total pulmonary resistance

Received August 4 , 1986; accepted May 21, 1987.

Correspondence Cleide Suguihara, M.D., Department of Pediatrics (R-131), University of Miami School of Medicine, P.O. Box 016960, Miami, FL 33101.

Supported in part by the National Institutes of Health Grants 1-R01-HD14940 and 5-R01-HL25023, The State of Florida, Department of Health and Rehabilitative Services, Children's Medical Services, and the University of Miami: Project Newborn. C.S. was supported by a research fellowship grant from $\mathrm{CNPq}-$ Conselho Nacional de Desenvolvimento Cientifico e Tecnologico, Brazil.

'Presented in part at the Society for Pediatric Research, Washington, D.C., May 7,1986 .

\author{
Tx, thromboxane \\ IV, intravenous
}

Experimentally induced group B streptococcal infection using live organisms or exotoxin, and infusions of Escherichia coli endotoxin result in dramatic alterations in cardiovascular function characterized by elevations in pulmonary artery pressure and pulmonary vascular resistance and decreases in cardiac output and oxygenation (1-9). These early hemodynamic manifestations of gram-positive and gram-negative infections appear to be mediated by products of the cyclooxygenase pathway, especially $\mathrm{TxA}_{2}$ and prostacyclin $(2,4-6,8-11)$. However, recent investigation (12) has shown that a leukotriene receptor antagonist, FPL 57231, ameliorates the early hemodynamic changes associated with an infusion of live GBS in piglets, suggesting a role for leukotriene $\mathrm{C}_{4}$ and $\mathrm{D}_{4}$. The possible effects of lipoxygenase products of arachidonic acid metabolism on GBS-induced changes in lung function in a young animal model have not been defined.

Alterations in pulmonary mechanics, which include decreased lung compliance and increased pulmonary resistance, have been reported with $E$. coli endotoxin infused in adult animals and have been attributed to products of arachidonic acid metabolism $(8,13-16)$. In fact, pretreatment with cyclooxygenase inhibitors prevents these early changes in lung mechanics after endotoxin infusion $(8,13,15,16)$. In these studies $\mathrm{TxA}_{2}$ has been implicated in the etiology of these abnormalities. Spannhake et al. (15), however, have questioned the relative contribution of $\mathrm{TxA}_{2}$ to these changes since they were unable to demonstrate a difference in lung compliance between control and endotoxin-treated animals after a Tx synthetase inhibitor was infused. These investigators postulated that either products of the lipoxygenase pathway or a decrease in the autoinactivation of cyclooxygenase may have played a role in the etiology of the pulmonary function abnormalities in endotoxin-treated animals.

The purpose of the present study was to define the role of cyclooxygenase and lipoxygenase products on the changes in pulmonary mechanics occurring secondary to an infusion of live GBS by administering indomethacin, a cyclooxygenase inhibitor, and FPL 57231, a leukotriene receptor antagonist to septic piglets.

\section{MATERIALS AND METHODS}

Animal model. Twenty-two piglets were anesthetized with pentobarbital $(30 \mathrm{mg} / \mathrm{kg}$, intraperitoneally). A femoral artery and vein were cannulated and used for Psa measurement, blood 
sampling, and the infusion of fluids and bacteria. A 5F SwanGanz thermodilution catheter was introduced into the right external jugular vein and advanced under fluoroscopy into the left pulmonary artery. This catheter was used to measure Ppa and Ppaw. Vascular pressures were measured with pressure transducers (model P23-1D; Gould Instruments, Cleveland, OH) and recorded on a multichannel recorder (Model 5 polygraph, S2925T25, Grass Instrument, Quincy, MA).

A tracheostomy was performed and a special $3.5 \mathrm{~mm}$ endotracheal tube inserted (Hi-Lo Tracheal Tube, NCC Division, Mallinckrodt Inc., Argyle, NY). This tube has a main lumen for ventilation and a separate pressure monitoring lumen (internal diameter, $1 \mathrm{~mm}$ ) that opens into the main lumen $0.5 \mathrm{~cm}$ above the distal end of the tube.

The animals were ventilated with a time-cycled, pressure limited, infant ventilator (Sechrist, Model IV-100 B Infant Ventilator, Sechrist Industries, Anaheim, CA). Ventilator settings included the following: peak inflation pressure of $12 \mathrm{~cm} \mathrm{H}_{2} \mathrm{O}$, positive end-expiratory pressure of $2 \mathrm{~cm} \mathrm{H}_{2} \mathrm{O}$, respiratory rate of 40 breaths $/ \mathrm{min}$, and inspiratory time of $0.50 \mathrm{~s}$. Animals were ventilated with room air, and respirator settings were not altered during the study period. Arterial blood gases were measured prior to and every $15 \mathrm{~min}$ until $60 \mathrm{~min}$ after the bacterial infusion was started (pH/Blood Gas Analyzer 113, Instrumentation Laboratories, Lexington, MA).

The rectal temperature was continuously monitored with a thermistor probe (Yellow Springs Instrument Co., Yellow Springs, $\mathrm{OH}$ ), and maintained at $38^{\circ} \mathrm{C}$ by means of a servo controlled radiant warmer.

The animals received an infusion of $6 \mathrm{ml} / \mathrm{kg} / \mathrm{h}$ of $5 \%$ dextrose solution through a peripheral vein and a heparinized saline solution $(10 \mathrm{U} / \mathrm{ml})$ through the pulmonary artery catheter.

The animals were paralyzed with pancuronium bromide by using an initial dose of $0.2 \mathrm{mg} / \mathrm{kg} \mathrm{IV}$, which was followed by a continuous infusion of $0.4 \mathrm{mg} / \mathrm{kg} / \mathrm{h}$. After allowing a $60-\mathrm{min}$ stabilization period, baseline cardiovascular measurements (Psa, $\mathrm{Ppa}$, and Ppaw), pulmonary mechanics (Cdyn and $\mathrm{R}_{\mathrm{L}}$ ) and arterial blood gases were obtained prior to bacterial infusion. These values will be hereafter referred to as baseline.

Systemic pressure and Ppa were measured continuously throughout the baseline and study periods and Ppaw measured prior to and during the bacterial infusion and at 15, 30, and 60 min after infusion of GBS was begun.

Pulmonary mechanics. Lung mechanics were measured prior to and 15,30 , and $60 \mathrm{~min}$ after onset of bacterial infusion. Respiratory flow was measured with a heated Fleisch no. 0 pneumotachometer (Oem Medical, Richmond, VA) placed between the endotracheal tube and ventilator circuit. The differential pressure output from the pneumotachometer was measured with a transducer (model MP 45, Validyne Engineering Co., Northridge, CA) and amplified by a pressure amplifier (Gould Instruments, Cleveland, OH). The pneumotachometer was calibrated using constant flows and a Tissot spirometer. Output was linear from 0 to $15 \mathrm{liter} / \mathrm{min}$. The flow signal was electronically integrated to obtain tidal volume using a Gould integrator amplifier. Calibration of tidal volume was done before and after each study using a calibrated glass syringe. An $8 \mathrm{~F}$ water filled feeding tube was placed in the lower esophagus to measure esophageal pressure by means of a pressure transducer (model P23-ID; Gould Instruments) and a Gould pressure amplifier calibrated with a water manometer. This tube was flushed before each recording of esophageal pressure. The tip of the tube was positioned in the lower portion of the esophagus by recording pressures while pulling the tube from the stomach into the esophagus. This position reduces cardiac artifact. The accuracy of the esophageal pressure signal was tested by comparing airway and esophageal pressure during airway occlusion before paralysis. Distal airway pressure was measured by connecting the monitor lumen of the endotracheal tube to a pressure transducer (model P23-ID; Gould Instruments) and amplifying the signal with a pressure amplifier. The response time for the distal airway pressure measurement was tested in vitro by simultaneously measuring pressure changes in a glass container directly using a Validyne pressure transducer (model MP-45, diaphragm no. 28, Validyne Engineering Co.) which has a flat frequency response up to $60 \mathrm{~Hz}$, and measuring the same pressure changes via the pressure monitoring line of the endotracheal tube (Hi-Lo) which was inserted inside the glass container. The difference in pressure measurements was less than $1.5 \%$ at rates up to $18 \mathrm{~Hz}$. Pressure changes were produced using a high frequency oscillator (BMO$20 \mathrm{~N}$, Hummingbird, Tokyo, Japan). Air flow, tidal volume, and airway and esophageal pressures were recorded on a multichannel recorder (model 2400; Gould Instruments). Cdyn was calculated by dividing the tidal volume by the change in transpulmonary pressure (airway pressure minus esophageal pressure) measured at the moment of zero flow between end-inspiration and end-expiration. $R_{L}$ was calculated at mid-tidal volume by determining the transpulmonary pressure difference between the points of midinspiration and midexpiration, and dividing this by the sum of the inspiratory and expiratory flows measured at the same points in time (17).

Bacterial preparation. Group B $\beta$-hemolytic streptococci (type Ic) were isolated from the blood of an infant who developed early onset sepsis at the University of Miami/Jackson Memorial Medical Center Neonatal Intensive Care Unit. Bacteria for each experiment were incubated $18 \mathrm{~h}$ in Todd-Hewitt broth at $37^{\circ} \mathrm{C}$. The broth culture was centrifuged at $1700 \mathrm{rpm}$ for $30 \mathrm{~min}$ and the bacterial pellet was resuspended in sterile Ringer's lactate solution with $5 \%$ dextrose to an approximate concentration of $1.5 \times 10^{9}$ colony forming units per $\mathrm{ml}$. The number of colony forming units was determined by serial plate dilutions.

Induction of sepsis. Bacterial infusion was begun immediately after baseline values were obtained. Bacteria were infused through a femoral vein at a rate calculated to deliver approximately $5 \times 10^{7}$ organisms $/ \mathrm{kg} / \mathrm{min}$. This infusion was continued throughout the entire study period. Fifteen min after the bacterial infusion was begun all measurements were repeated and the animals were randomly assigned to one of three groups. For groups receiving drug therapy, administration of indomethacin and FPL 57231 were begun immediately after the measurements were completed.

The untreated group $(n=7)$ (mean $\pm \mathrm{SD}$; weight, $2677 \pm 501$ g; age, $10 \pm 2$ days) received only bacteria throughout the study period. The indomethacin group $(n=8)$ (weight, $2419 \pm 213 \mathrm{~g}$; age, $9 \pm 3$ days) received GBS and a cyclooxygenase inhibitor, indomethacin ( $3 \mathrm{mg} / \mathrm{kg} \mathrm{IV)}$. The FPL group $(n=7)$ (weight, $2848 \pm 623 \mathrm{~g}$; age, $11 \pm 2$ days) received the GBS and leukotriene receptor antagonist, FPL $57231(1 \mathrm{mg} / \mathrm{kg} / \mathrm{min}$ IV for $30 \mathrm{~min}$ followed by $0.5 \mathrm{mg} / \mathrm{kg} / \mathrm{min}$ for $30 \mathrm{~min}$ ) (Fisons Ph, Loughborough, England).

Assay for $T \times B_{2}$. Blood samples were obtained from untreated and treated animals for radioimmunoassay of $\mathrm{TxB}_{2}$, the stable metabolite of $\mathrm{TxA}_{2}$, and collected in tubes containing aspirin and EDTA $(0.41$ and $1.95 \mathrm{mg} / \mathrm{ml}$ for $1 \mathrm{ml}$ blood, respectively). Plasma from these samples was extracted with ethanol, centrifuged to remove precipitated protein and dried under nitrogen before being reconstituted in $0.5-1.0 \mathrm{ml}$ of phosphate-buffered saline containing $0.1 \%$ gelatin. The method used for their determination has been described previously (2). Values were drawn prior to infusion of GBS and 15, 30, and $60 \mathrm{~min}$ after the infusion was begun.

Data analyses. Data are expressed as mean \pm SEM. To ensure that there were no differences in initial values among the groups, a one-way analysis of variance was performed at baseline and 15 min after GBS infusion. The changes from baseline to $15 \mathrm{~min}$ after infusion of GBS was started were compared using a matched paired $t$ test. The paired $t$ test was also used to compare values from 15 to $60 \mathrm{~min}$. Repeated measure analysis of variance was used to compare the pattern of response to treatment over time from a point $15 \mathrm{~min}$ after GBS infusion was started to the 
subsequent points for the three groups for all variables. To further elucidate the changes from $15 \mathrm{~min}$ post-GBS infusion to $60 \mathrm{~min}$, values were expressed as a percent of baseline and evaluated with one-way analysis of variance followed by Duncan's multiple range test using a $p$ of 0.05 . The correlations between Cdyn and $\overline{\mathrm{P} p a}, \overline{\mathrm{P}} \mathrm{paw}$, and $\mathrm{TxB}_{2}$ were obtained by using linear correlation analyses and power curves.

\section{RESULTS}

Lung mechanics, arterial blood gases, and $\overline{\mathrm{P}} \mathrm{pa}$ and $\overline{\mathrm{P}}$ paw values at baseline and $15 \mathrm{~min}$ after the onset of bacteria infusion did not differ among the three groups. Combining all groups, the data showed that after 15 min of GBS infusion, $\mathrm{PaO}_{2}$ decreased from $81 \pm 2$ to $46 \pm 2 \mathrm{~mm} \mathrm{Hg}(p<0.001)$ while $\mathrm{PaCO}_{2}$ increased from $29 \pm 1$ to $36 \pm 2 \mathrm{~mm} \mathrm{Hg}(p<0.001)$. Mean pulmonary artery pressure increased from $13 \pm 1$ to $46 \pm 1 \mathrm{~mm} \mathrm{Hg}(p<$ $0.001)$ and $\bar{P}$ paw from $2.4 \pm 0.3$ to $7.6 \pm 0.6 \mathrm{~mm} \mathrm{Hg}(p<$ $0.001)$. Tidal volume decreased from $11.39 \pm 0.58$ to $8.53 \pm$ $0.46 \mathrm{ml} / \mathrm{kg}(p<0.001)$ while the transpulmonary pressure increased from $8.08 \pm 0.32$ to $8.90 \pm 0.33 \mathrm{~cm} \mathrm{H}_{2} \mathrm{O}(p<0.001)$ due to a decrease in Cdyn from $1.45 \pm 0.09$ to $1.00 \pm 0.07 \mathrm{ml} /$ $\mathrm{cm} \mathrm{H}_{2} \mathrm{O} / \mathrm{kg}(p<0.001)$. The inspiratory flow decreased from $6.17 \pm 0.20$ to $5.72 \pm 0.20$ liter $/ \mathrm{min}(p<0.001)$ while the transpulmonary pressure at mid-tidal volume increased from $2.78 \pm 0.14$ to $3.24 \pm 0.20 \mathrm{~cm} \mathrm{H}_{2} \mathrm{O}(p<0.02)$, as a result of an increase in $\mathrm{R}_{\mathrm{L}}$ from $13.5 \pm 0.5$ to $18.3 \pm 1.0 \mathrm{~cm} \mathrm{H}_{2} \mathrm{O} /$ liter $/ \mathrm{s}(p$ $<0.001)$. The time constant of the respiratory system $\left(\mathrm{R}_{\mathrm{L}} \times\right.$ Cdyn) was $0.0497 \pm 0.0025$ prior to and $0.0461 \pm 0.002 \mathrm{~s} 15$ min after the infusion of GBS was begun. These values were not significantly different.

Arterial oxygen tension remained low throughout the study period in the untreated group (Table 1). In contrast, $\mathrm{PaO}_{2}$ increased toward baseline values over the study period and was significantly different at 30 and $60 \mathrm{~min}$ in the indomethacin group compared to untreated animals (Table 1). In the FPL group, the $\mathrm{PaO}_{2}$ increased slowly, and a statistically significant difference occurred from the untreated group at $60 \mathrm{~min}$ of bacterial infusion. The arterial carbon dioxide tension was not different between groups.

After an initial increase in Ppa with GBS infusion, the $\bar{P}$ pa

Table 1. Effect of GBS infusion on gas exchange and plasma $T X B_{2}$ for all experiments (mean $\left.\pm S E M\right)$ in untreated $(n=7)$, indomethacin $(n=8)$, and FPL $(n=7)$ groups

\begin{tabular}{ccc}
\hline $\mathrm{PaO}_{2}$ & $\mathrm{PaCO}_{2}$ & $\mathrm{TxB}_{2}$ \\
$(\mathrm{~mm} \mathrm{Hg})$ & $(\mathrm{mm} \mathrm{Hg})$ & $(\mathrm{ng} / \mathrm{ml})$ \\
\hline
\end{tabular}

Baseline

$\begin{array}{llll}\text { Untreated } & 78 \pm 4 & 28 \pm 2 & 0.633 \pm 0.238 \\ \text { Indomethacin } & 82 \pm 4 & 28 \pm 1 & 0.440 \pm 0.047 \\ \text { FPL } & 82 \pm 4 & 33 \pm 4 & 0.707 \pm 0.145\end{array}$

Post-GBS infusion

$15 \mathrm{~min}$

$\begin{array}{llll}\text { Untreated } & 46 \pm 5 & 35 \pm 4 & 8.359 \pm 2.715 \\ \text { Indomethacin } & 48 \pm 3 & 36 \pm 2 & 6.515 \pm 1.563 \\ \text { FPL } & 46 \pm 2 & 37 \pm 2 & 5.937 \pm 1.232\end{array}$

$30 \mathrm{~min}$

$\begin{array}{lllc}\text { Untreated } & 46 \pm 4 & 36 \pm 5 & 15.264 \pm 6.089 \\ \text { Indomethacin } & 70 \pm 3^{*} & 33 \pm 2 & 2.087 \pm 0.467 \dagger \\ \text { FPL } & 55 \pm 4 & 36 \pm 3 & 9.907 \pm 1.781\end{array}$

$60 \mathrm{~min}$

\begin{tabular}{lllc} 
Untreated & $47 \pm 3$ & $38 \pm 5$ & $16.307 \pm 5.823$ \\
Indomethacin & $69 \pm 4^{*}$ & $33 \pm 2$ & $1.010 \pm 0.271 \dagger$ \\
FPL & $59 \pm 4 \dagger$ & $37 \pm 3$ & $15.301 \pm 2.401$ \\
\hline
\end{tabular}

${ }^{*} p<0.01 \dagger p<0.05$, significance refers to comparison of untreated to treated. remained fairly stable with a gradual decline over time in the untreated group (Fig. 1). Animals treated with indomethacin displayed a dramatic decrease in $\bar{P}$ pa to values which were significantly lower than those of the untreated group. FPLtreated animals also had a significant decrease in Ppa when compared to the untreated group, however, this decline was more gradual than in the indomethacin group. Pulmonary wedge pressure increased throughout the study period in untreated animals (Fig. 1). The decrease in Ppaw in both treated groups was significantly different from the untreated group.

Lung compliance fell with infusion of GBS by $15 \mathrm{~min}$ and remained low throughout the study period in untreated animals (Fig. 2). In the FPL group Cdyn was not significantly different from untreated animals, however, indomethacin-treated animals showed a significant improvement in Cdyn. There was a negative correlation between Cdyn and Ppa $\left(\mathrm{y}=1.62 \mathrm{x}^{-0.016}, r=-0.55\right.$, $p<0.001)$ as well as between Cdyn and Ppaw ( $\mathrm{y}=1.44 \mathrm{x}^{-0.23}, r$ $=-0.61, p<0.001)$ when all groups were combined.

Pulmonary resistance increased significantly by $15 \mathrm{~min}$ after bacteria infusion in all groups and was represented by a mean percent change from baseline of approximately $40 \%$ (Fig. 2). Pulmonary resistance was not statistically different between groups during the study period in either absolute values or as a percent change from baseline. Although both treatment groups showed a tendency for pulmonary resistance to decrease by 60 min, only in the indomethacin group did the pulmonary resistance at $60 \mathrm{~min}$ become significantly lower than the 15-min value.

Mean $\mathrm{TxB}_{2}$ levels at 15 min were significantly increased $(p<$ 0.01 ) compared to baseline values in all the groups and remained elevated in the untreated and FPL groups (Table 1). In the indomethacin group, $\mathrm{TxB}_{2}$ decreased significantly and remained low throughout the study period. There was a negative correlation between Cdyn and $\mathrm{TxB}_{2}$ levels $\left(\mathrm{y}=1.30 \mathrm{x}^{-0.16}, r=-0.60\right.$, $p<0.01$ ), in this group.
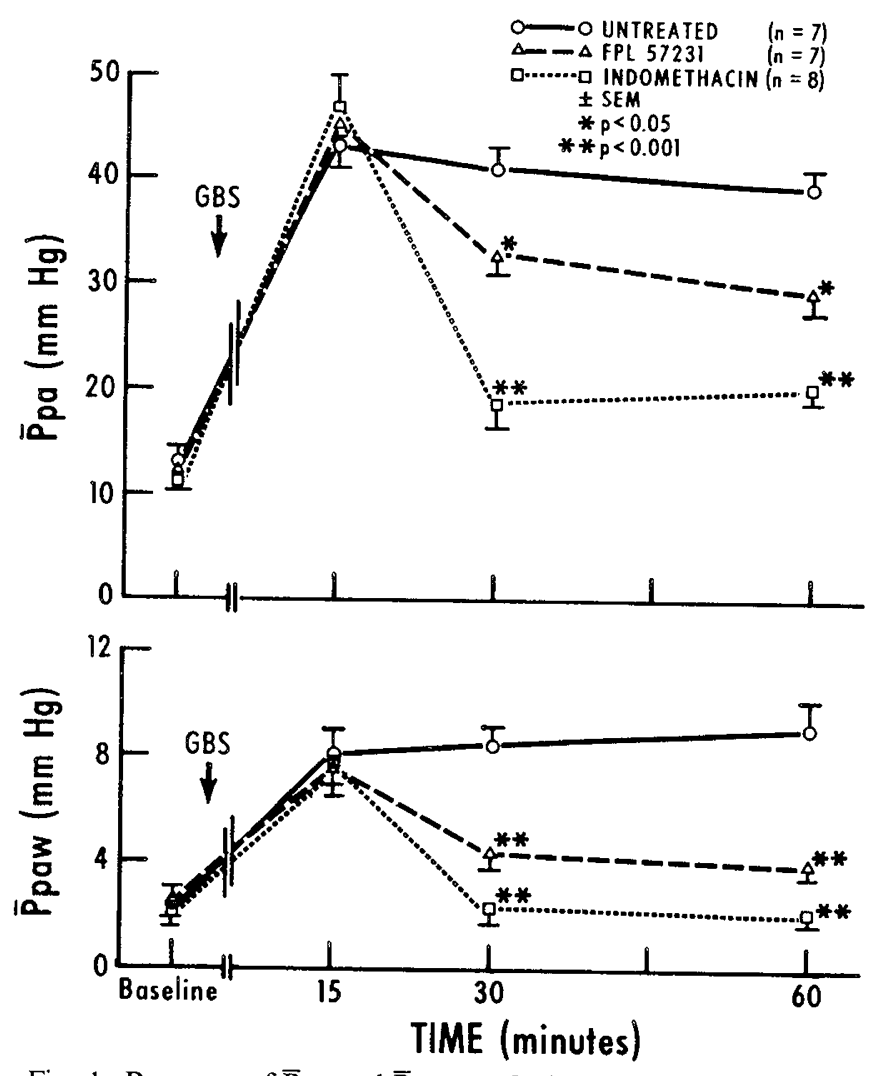

Fig. 1. Response of Ppa and Ppaw to GBS infusion. ${ }^{* * * *}$ Significant difference refers to comparison of untreated to treated group. 

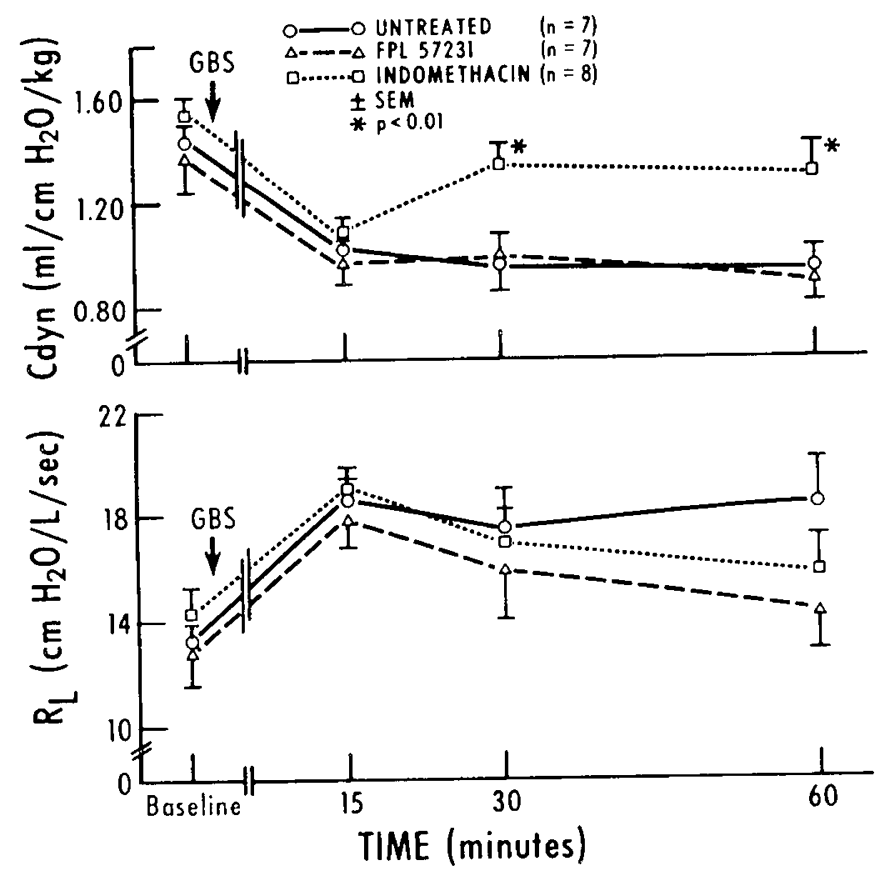

Fig. 2. Responses of Cdyn and $\mathrm{R}_{\mathrm{L}}$ to GBS infusion. * Significant difference refers to comparison of untreated to treated group.

\section{DISCUSSION}

The results of the present study suggest that the early changes in pulmonary compliance and resistance occurring after an infusion of live-GBS are largely mediated by cyclooxygenase products of arachidonic acid. This is consistent with previously published data showing that cyclooxygenase metabolites were responsible for the changes in pulmonary mechanics observed in E. coli endotoxin-treated animals $(8,13,15,16)$.

Some investigators have also suggested that the changes in lung function during sepsis may also be mediated by lipoxygenase products of arachidonic acid metabolism (15). This is supported by studies in which $E$. coli endotoxin infusion resulted in increased concentrations of lipoxygenase as well as cyclooxygenase products in plasma and lung lymph $(5,16,18,19)$. In addition, there is also evidence that leukotriene $C_{4}$ and $D_{4}$ play a role in the early as well as late cardiovascular and pulmonary manifestations of both $E$. coli endotoxin $(20)$ and GBS sepsis $(12,21)$. The present data, however, do not support a significant role for leukotriene $C_{4}$ and $D_{4}$ in the pulmonary manifestations of sepsis secondary to GBS in a young animal model. These results differ from those reported for $E$. coli endotoxin-treated adult animals in which FPL 57231 completely blocked the endotoxin-induced changes in Cdyn and $R_{L}(20)$. The reason for this difference is not clear but may involve the use of endotoxin at sublethal doses in adult sheep as opposed to our use of a lethal dose of live-GBS bacteria in piglets. In addition, our animals were treated after the GBS infusion began while previous studies involved pretreated animals.

The changes in lung mechanics noted in this study were associated with increases in $\overline{\mathrm{P}} \mathrm{pa}$ and $\overline{\mathrm{P}}$ paw. Investigators have described alterations in lung compliance with increases in pulmonary blood volume secondary to an increase in left atrial pressure alone or with elevated Ppa (22-26). The resulting pulmonary vascular engorgement has been shown to produce a 20 to $40 \%$ decrease in lung compliance in laboratory animals with normal lungs when left atrial pressure is increased to $10-25 \mathrm{~mm}$ $\mathrm{Hg}(23)$. Although the mechanism for this is unclear, it is possible that competition between pulmonary blood and gas volume within certain ranges of vascular and transpulmonary pressures may cause changes in functional residual capacity and/or a reduction in the caliber of the terminal airways (23). This may result in a decrease in pulmonary compliance. It is also possible that an increase in pulmonary vascular rigidity secondary to vascular engorgement may effect lung function.

Our data suggest a relationship between Cdyn and $\bar{P}$ pa and $\bar{P}$ paw. However, the magnitude of increase in $\bar{P}$ paw in the present study was less than those cited above $(22,23,26)$, making it unlikely that changes in vascular pressure measured in our study alone resulted in alterations in lung function. One difference between the present study and those cited previously that may influence the magnitude of the changes in vascular pressure and lung function is the presence of pulmonary pathology in our subjects. Previous work (22-26) evaluating the relationship between vascular pressure changes and lung function were performed using animals with normal lungs.

Another possible explanation for these changes in lung function during sepsis may involve edema formation. During GBS infusion there is an abrupt rise in lymph flow accompanied by a decreased lymph to plasma protein concentration ratio (1). This is thought to result from an increase in microvascular hydrostatic pressure (8). In addition, there is evidence that changes in vascular permeability begin within $30 \mathrm{~min}$ of $E$. coli endotoxin infusion in sheep (27). Although changes in lung compliance occur prior to significant interstitial or alveolar edema $(7,28)$ these changes in edema formation which appear early may in part contribute to the alterations in lung compliance and explain why in this study Cdyn does not return to baseline despite treatment with indomethacin. Changes in pulmonary mechanics secondary to hypoxia should also be considered, however, it is unlikely that the decreases in Cdyn can be explained by hypoxia alone, for hypoxia causes only modest alterations in lung mechanics (29).

Elevation in $\mathrm{TxA}_{2}$ has been correlated with a decrease in Cdyn. Both changes may be blocked by a selective inhibitor to $\mathrm{TxA}_{2}$ synthesis (30). In the present study, there was a correlation between $\mathrm{Cdyn}$ and $\mathrm{TxB}_{2}$ in the indomethacin group, but this does not necessarily imply a causal relationship. We speculate that $\mathrm{TxB}_{2}$ may mediate changes in Cdyn, but as other products of arachidonic acid metabolism ( e.g. prostaglandin $\mathrm{F}_{2} \alpha$ ) were not measured, their role cannot be excluded.

Infusions of $E$. coli endotoxin and GBS exotoxin into both adult and neonatal animals have resulted in a 3- to 10-fold increase in $\mathrm{R}_{\mathrm{L}}$, a finding that can be prevented by cyclooxygenase inhibitors $(7,13,15,16,18,31)$. This dramatic increase in $R_{L}$ contrasts to the modest increase observed in the present study. Although treatment resulted in a decrease in $R_{L}$ in this animal model the results were not statistically different from the untreated group. The lack of marked changes in $R_{L}$ before and after treatment may be partially explained by the use of young piglets who have less airway smooth muscle (32) and may therefore not have the ability to develop significant bronchoconstriction. Lung volume was not measured and as a result the possibility that an increase in volume due to increased resistance may have dampened the effect of the GBS infusion on $R_{L}$ cannot entirely be excluded. However, the likelihood of gas trapping is small because the time constant of the respiratory system did not change after the bacterial infusion. In addition, the expiratory time was almost 20 times longer than the time constant, making gas trapping unlikely.

In summary, these data suggest that the acute decrease in lung compliance in GBS infection may, in part, be mediated by cyclooxygenase byproducts of arachidonic acid metabolism. We speculate that the fall in Cdyn may be partially related to a combination of pulmonary vascular engorgement and edema.

Acknowledgments. The authors express their thanks to Ralph N. Cicalese for his indispensable technical assistance throughout this project, to Dr. Murray Streitfeld for his preparation of the bacteria, to Janet Cassidy and Bill Feuer for their statistical guidance, to Dr. Shahnaz Duara for her critical review of this manuscript, and Cristina Varga for her excellent secretarial support. 


\section{REFERENCES}

1. Rojas J, Green RS, Hellerqvist CG, Olegard R, Brigham KL, Stahlman MT 1981 Studies on group B $\beta$-hemolytic streptococcus. II. Effects on pulmonary hemodynamics and vascular permeability in unanesthetized sheep. Pediatr Res 15:899-904

2. Runkle B, Goldberg RN, Streitfeld MM, Clark MR, Buron E, Setzer ES, Bancalari E 1984 Cardiovascular changes in group B streptococcal sepsis in the piglet: response to indomethacin and relationship to prostacyclin and thromboxane A2. Pediatr Res 18:874-878

3. Sorensen GK, Redding GJ, Truog WE 1985 Mechanisms of pulmonary gas exchange abnormalities during experimental group B streptococcal infusion. Pediatr Res 19:922-926

4. Fletcher JR, Ramwell PW, Herman CM 1976 Prostaglandins and the hemodynamic course of endotoxin shock. J Surg Res 20:589-594

5. Demling RH, Smith M, Gunther R, Flynn JT, Gee MH 1981 Pulmonary injury and prostaglandin production during endotoxemia in conscious sheep. Am J Physiol 240:H348-353

6. Ogeltree ML, Brigham KL 1982 Effects of cyclooxygenase inhibitors on pulmonary vascular responses to endotoxin in unanesthetized sheep. Prostaglandins Leukotrienes Med 8:489-502

7. Esbenshade AM, Newman JH, Lams PM, Jolles H, Brigham KL 1982 Respiratory failure after endotoxin infusion in sheep: lung mechanics and lung fluid balance. J Appl Physiol 53:967-976

8. Olson NC, Brown Jr TT, Anderson DL 1985 Dexamethasone and indomethacin modify endotoxin-induced respiratory failure in pigs. J Appl Physiol 58:274-284

9. Kubo K, Kobayashi T 1985 Effects of OKY-046, a selective thromboxane synthetase inhibitor, on endotoxin-induced lung injury in unanesthetized sheep. Am Rev Respir Dis 132:494-499

10. Rojas $\Upsilon$, Larsson LE, Ogletree ML, Brigham KL, Stahlman MK 1983 Effects of cyclooxygenase inhibition on the response to group B streptococcal toxin in sheep. Pediatr Res 17:107-110

11. Fletcher JR, Ramwell PW, Harris RH 1981 Thromboxane, prostacyclin, and hemodynamic events in primate endotoxin shock. Adv Shock Res 5:143148

12. Goldberg RN, Suguihara C, Streitfeld MM, Bancalari A, Clark MR, Bancalari E 1986 Effects of leukotriene antagonist on the early hemodynamic manifestations of group B streptococcal sepsis in piglets. Pediatr Res 20:10041008

13. Snapper JR 1981 Septic pulmonary edema. Sem Respir Med 3:92-96

14. Coker SJ, Hughes B, Parratt JR, Rodger IW, Zeitlin IJ 1983 The release of prostanoids during the acute pulmonary response to $\mathrm{E}$. coli endotoxin in anaesthetized cats. Br J Pharmacol 78:561-570

15. Spannhake EW, Colombo JL, Craigo PA, McNamara DB, Hyman AL, Kadowitz PJ 1983 Evidence for modification of pulmonary cyclooxygenase activity by endotoxin in the dog. J Appl Physiol 54:191-198

16. Snapper JR, Hutchison AA, Ogletree ML, Brigham KL 1983 Effects of cyclooxygenase inhibitors on the alterations in lung mechanics caused by endotox- emia in the unanesthetized sheep. J Clin Invest 72:63-76

17. Geubelle F, Senterre J 1970 Methods of investigation of the mechanics of breathing in the artificially ventilated newborn. Biol Neonate 16:35-46

18. Hinson Jr JM, Hutchison AA, Ogletree ML, Brigham KL, Snapper JR 1983 Effect of granulocyte depletion on altered lung mechanics after endotoxemia in sheep. J Appl Physiol 55:92-99

19. Ogletree M, Oates J, Brigham K, Hubbard W 1982 Evidence for pulmonary release of 5-hydroxyeicosa-tetraenoic acid (5-HETE) during endotoxin induced leukopenia and increased lung vascular permeability in unanesthetized sheep. Prostaglandins 23:459-468

20. Ahmed T, Wasserman MA, Muccitelli R, Tucker S, Gazeroglu H, Marchette B 1986 Endotoxin-induced changes in pulmonary hemodynamic and respiratory mechanics. Role of lipoxygenase and cyclooxygenase products. Am Rev Respir Dis 134:1149-1157

21. Goldberg RN, Suguihara C, Streitfeld MM, Bancalari A, Clark MR, Bancalari E 1986 Effects of leukotriene antagonist FPL 57231 on the late hemodynamic manifestations of group B Beta streptococcal sepsis (GBS) in piglets. Pediatr Res 20:396A(abstr)

22. Borst HG, Berglund E, Whittenberger JL, Mead J, McGregor M, Collier C 1957 The effect of pulmonary vascular pressures on the mechanical properties of the lungs of anesthetized dogs. J Clin Invest 36:1708-1714

23. Hauge A, Bo G, Waaler BA 1975 Interrelations between pulmonary liquid volumes and lung compliance. J Appl Physiol 38:608-614

24. Hughes R, May AJ, Widdicombe JG 1958 The effect of pulmonary congestion and oedema on lung compliance. J Physiol 142:306-313

25. Noble WH, Kay JC, Obdrzalek K 1975 Lung mechanics in hypervolemic pulmonary edema. J Appl Physiol 38:681-687

26. Gray BA, McCaffree DR, Sivak ED, McCurdy HT 1978 Effect of pulmonary vascular engorgement on respiratory mechanics in the dog. J Appl Physiol 45:119-127

27. Meyrick B, Brigham K 1983 Acute effects of E. coli endotoxin on the pulmonary microcirculation of anesthetized sheep. Structure: function relation ships. Lab Invest 48:458-470

28. McCaffree DR, Gray BA, Pennock BE, Coalson J, Bridges C, Taylor FB, Rogers RM 1981 Role of pulmonary edema in the acute pulmonary response to sepsis. J Appl Physiol 50:1198-1205

29. La Framboise WA, Guthrie RD, Standaert TA, Woodrum DE 1983 Pulmonary mechanics during the ventilatory response to hypoxemia in the newborn monkey. J Appl Physiol 55:1008-1014

30. Tilden SJ, Cowen KH, Wegmann MJ, Kadowitz PJ 1982 Evidence that the airway effects of arachidonic acid are largely due to thromboxane. Clin Res 30:911 A(abstr)

31. Englehardt B, Sandberg K, Bratton D, Van den Abbeele A, Grogaard J, Hellerqvist C, Sundell $H 1987$ The role of granulocytes in the pulmonary response to group B streptococcal toxin in young lambs. Pediatr Res 21:159 165

32. Rendas A, Branthwaite M, Reid L 1978 Growth of pulmonary circulation in normal pig-structural analysis and cardiopulmonary function. J Appl Physiol 45:806-817 